\title{
The influence of the bimodal stimulation on the auditory ability of temporal ordering
}

Maria Madalena Canina Pinheiro' https://orcid.org/0000-0003-1726-9703

Patrícia Ilsi Welter ${ }^{2}$ https://orcid.org/0000-0003-3536-8852

Jaqueline Cardoso Estácio ${ }^{2}$ https://orcid.org/0000-0003-3746-2551
Universidade Federal de Santa Catarina - UFSC, Centro de Ciências da Saúde, Departamento de Fonoaudiologia, Florianópolis, Santa Catarina, Brasil. ${ }^{2}$ Universidade Federal de Santa Catarina - UFSC, Curso de Fonoaudiologia, Florianópolis, Santa Catarina, Brasil.

Conflict of interests: Nonexistent

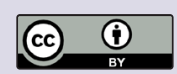

Received on: October 30, 2019 Accepted on: March 31, 2020

\section{Corresponding Address:}

Maria Madalena Canina Pinheiro

Centro de Ciências da Saúde - CCS,

Curso de Fonoaudiologia,

Campus Universitário - Trindade

Rua Delfino Conte, $s$ / número

CEP: 88040-900 - Florianópolis,

Santa Catarina, Brasil

E-mail: madalena.pinheiro@ufsc.br

\section{ABSTRACT}

Objective: to analyze temporal ordering auditory ability in unilateral cochlear implant users with bimodal stimulation.

Methods: the study included 15 unilateral cochlear implant users, six with bimodal stimulation and nine with exclusive cochlear implant and a control group consisting of 15 hearing individuals. Both groups underwent the standard duration and the standard frequency tests for temporal ordering auditory ability analysis. In the inferential analysis of the data, the nonparametric statistical tests Mann-Whitney and Kruskal-Wallis were used $(p<0,05)$.

Results: there was a significant difference in the performance of the standard frequency test, and subjects with bimodal stimulation presented a better performance than those with exclusive cochlear implants. The standard frequency test was associated with education and speech therapy. On the other hand, in the standard duration test, there was a relation with the implanted ear. The most frequent errors were discrimination for both temporal tests.

Conclusion: bimodal stimulation, education and speech therapy influenced the performance of the frequency pattern test, while the implanted side influenced the performance of the duration pattern test.

Keywords: Hearing; Hearing Loss; Cochlear Implant; Auditory Perception; Hearing Tests 


\section{INTRODUCTION}

The sense of hearing is fundamental for the development of oral communication and, consequently, for human social interaction. The auditory system transmits environmental and speech sounds to the auditory cortex, where the information is processed to produce a perception of the signal ${ }^{1}$. Auditory alterations can seriously impact quality of life, affecting social, professional and psychological aspects of the individual.

Currently, the electronic devices most used in hearing rehabilitation of individuals with hearing loss are the Individual Sound Amplification Device (ISAD) and the Cochlear Implant $(\mathrm{Cl})^{2,3}$. The use of hearing aids can benefit individuals with mild to profound hearing loss. However, as they are sound amplifiers, a sufficient cochlear reserve for good speech perception is required. Individuals who have a bilateral high-grade hearing impairment, and have no benefit from the use of hearing aids, are candidates for the use of $\mathrm{Cl}^{4}$.

The use of unilateral $\mathrm{Cl}$ and of contralateral hearing aid to the implanted ear is called bimodal stimulation. This stimulation can be a good option to improve communication of individuals who have auditory residue in the non-implanted ear, bringing benefits such as improved sound localization, speech recognition in both silence and noise $\mathrm{e}^{5,6}$.

For the perception of speech sounds to occur properly, the integrity of the peripheral and central auditory pathway is important, as the presence of alterations can cause losses in the processing of the information received ${ }^{7}$. The $\mathrm{Cl}$ promotes important changes in the auditory restoration and in the users' well-being; however there is still a great variability in the performance of this population ${ }^{8}$.

Central Auditory Processing (CAP) refers to the efficiency and effectiveness with which the Central Auditory Nervous System (CANS) uses the auditory information. However, factors such as cognitive aspects, experience and the individual's motivation can influence the analysis of the acoustic signal? .

The CAP presents a set of fundamental auditory skills for the processing of verbal and non-verbal information, including temporal aspects composed by the ability to integrate, discriminate, mask and temporal processing 9 . In Brazil, temporal ordering and resolution skills are the most evaluated aspects in clinical test batteries ${ }^{10}$.

The auditory ability of temporal ordering refers to the ability to process multiple sound stimuli according to the order in which they appear over a period of time.
The temporal processing can be considered the basis for the development of most of the auditory processing skills; this is due to the influence of time on the characteristics that encompass hearing information ${ }^{11}$.

CANS functions are in some way subject to the influence of time. Speech and language comprehension depend on the ability to work with sound sequences ${ }^{12}$.

Currently in clinical practice, the Frequency Pattern Test (FPT) and the Duration Pattern Test (DPT) are the most used to assess the temporal ordering ability ${ }^{13}$. These tests involve the ability to order the frequency and duration of sounds and the recognition of acoustic aspects over time ${ }^{10}$.

The relationships between signal processing by the central auditory system and the use of $\mathrm{Cl}$ are still sources of several investigations that associate the benefits of using the device to individual auditory perception and of other non-auditory factors ${ }^{14,15}$. Investigations have already sought to review the temporal skills of resolution and temporal ordering in post-lingual $\mathrm{Cl}$ users using DPT, FPT and the Gaps in Noise (GIN) test ${ }^{3,16}$. The limited production of research in this area impairs knowledge and the development of new technologies that can benefit this population.

The aim of this study was to analyze the auditory ability of temporal ordering in users of unilateral cochlear implant and those with bimodal stimulation, in addition to the influence of socio-demographic variables, device usage time and speech therapy.

\section{METHODS}

The study was submitted to and approved by the Research Ethics Committee (REC) of the Federal University of Santa Catarina, SC, Brazil, under number 2,054,587 and CAAE number 65513617.4.0000.0121. This is a quantitative, descriptive, experimental, crosssectional investigation. Participants were properly guided and accepted to participate in the investigation on a voluntary basis after signing the Free and Informed Consent Form (FICF).

The population was divided into two groups: Study Group (SG) and Control Group (CG). The SG was composed of 15 individuals using unilateral IC, while the $C G$ was composed of 15 individuals matching the SG, according to gender and age. A maximum difference of five years was used in the age parameter.

The inclusion criteria of the SG included: sensorineural hearing loss of pre or post-lingual origin, severe or profound degree bilaterally, results $\geq 70 \%$ in the 
recognition of sentences in an open set ${ }^{17}$, Brazilian Portuguese as first language and continuous use of $\mathrm{Cl}$ for at least one year. The medical records were screened in order to obtain information regarding socio-demographic data (gender, age and education), use of bimodal stimulation and speech therapy. The SG was further subdivided into users of exclusive $\mathrm{Cl}$ and users of contralateral $\mathrm{CI}+$ ISAD.

The inclusion criteria for the $C G$ included: presence of auditory thresholds up to $40 \mathrm{~dB}$ at frequencies from $250 \mathrm{~Hz}$ to $4 \mathrm{kHz}$ bilaterally ${ }^{18}$, speech recognition consistent with pure-tone audiometry and having Brazilian Portuguese as the first language. To assess the presence of behavioral manifestations of the Central Auditory Processing Disorder (CAPD), the Scale of Auditory Behaviors (SAB) questionnaire was applied) ${ }^{19}$.

Exclusion criteria included conductive impairment, musical knowledge and the presence of evident neurological or cognitive changes.

The procedures performed in the SG included: DPT and FPT. The individuals that used bimodal stimulation $(\mathrm{Cl}+$ contralateral ISAD) were initially evaluated only with the $\mathrm{Cl}$ and later with both devices.

The procedures performed in the CG were: meatoscopy; basic audiological evaluation with investigation of auditory thresholds in the frequencies from 250 to $8 \mathrm{kHz}^{18}$, logoaudiometry composed by the Speech Recognition Threshold (SRT) and Speech Recognition Percentage Index (IPRF) ${ }^{20}$; Immittanciometry screening ${ }^{21}$; DPT and FPT ${ }^{22,23}$. The audiological evaluation was performed in an acoustically treated booth, using supra-aural headphones model TDH39, two channels audiometer model AC40 and immittance meter model AT235, both from Interacoustics.

$C G$ participants also answered the SAB questionnaire, which consists of 12 questions related to auditory processing; their score can vary from 12 to 60 points $^{19}$.

The temporal tests were applied in the same order, in both groups ( $C G$ and $S G$ ), initially the DPT and later the FPT. For each test, 30 sequences were presented containing three stimuli each. In DPT, the stimuli differ in duration, and could be long ( $L=500 \mathrm{~ms}$ ) or short (C $=250 \mathrm{~ms}$ ). The participants were instructed to verbally name the order in which the stimuli appear in each sequence; a total of six combination possibilities were presented: LLC, LCL, CLL, CCL, CLC and LCC ${ }^{22}$.

In FPT, the stimuli differed in frequency, being severe $(G=880 \mathrm{~Hz})$ or acute $(A=1122 \mathrm{~Hz})$; in all there are six combination possibilities presented in different ways: AAG, AGA, GAA, GGA, GAG and AGG.
Participants were instructed to give the correct name to the sequences ${ }^{23}$. In both tests, the first six sequences represented a form of training.

The temporal tests were applied in a free field in an acoustically treated cabin, using a speaker located one meter $(1 \mathrm{~m})$ away from the subject positioned at zero $(0 \circ)$ azimuth. The tests were recorded in a compact disc and were presented in an Asus notebook coupled to the two-channel audiometer, Interacoustics, AC40 model.

The temporal tests were applied with an intensity of $50 \mathrm{dBNS}$, according to the auditory threshold obtained from the average of the frequencies of $500 \mathrm{~Hz}, 1 \mathrm{kHz}$ and $2 \mathrm{kHz}$. For the $\mathrm{SG}$, the tests were applied based on the tritonal mean with the $\mathrm{Cl}$ connected. In both tests the errors were classified as inversion (example: CLC for CCL or AGG for GGA) or discrimination (example: CLC for LCL or AGG for GAA).

The data were tabulated in an electronic spreadsheet and then a descriptive analysis was performed regarding the variables gender, age, education, length of $\mathrm{Cl}$ use, implanted ear, speech therapy and use of bimodal stimulation.

Mann-Whitney and Kruskal-Wallis non-parametric tests were used for inferential statistical analysis of the data. The Mann-Whitney test was used to verify the association between $S G$ and $C G$ performance for both temporal tests, besides checking the association between DPT and FPT and the socio-demographic variables, audiological aspects, speech therapy and the use of bimodal stimulation .

The Kruskal-Wallis test was used to verify an association between the performance of DPT and FPT with education. The $p$-value was considered significant for values lower than $5 \%(p<0.05)$ and is represented with a superscript asterisk $\left(^{*}\right)$.

\section{RESULTS}

The SG population was composed of 15 individuals using unilateral $\mathrm{Cl}$; four of them were males and 11 females. The age range varied between 23 and 68 years of age, with an average of 48 years. Regarding education, nine subjects completed elementary school, four attended high school and only two had higher education. The CG was composed of 15 individuals, five male and ten female, aged 21 years to 65 years (mean 45.5 years). As for education, one subject attended elementary school, seven completed high school and seven completed higher education. The average score in the $S A B$ questionnaire was high 
(48.37 points), showing that the population in question had no complaints suggesting CAO Disorder.

Table 1 shows the numerical and percentage distribution of the auditory aspects of the SG. It should be observed that the majority of the subjects evaluated had the $\mathrm{Cl}$ on the right side and that most of them did not use the bimodal stimulation, in addition to the fact that most of them had already undergone speech therapy.

Table 2 shows the performance of SG and CG individuals for temporal tests.

Table 1. Numerical and percentage distribution of auditory aspects of the population using cochlear implants $(n=15)$

\begin{tabular}{cccc}
\hline \multicolumn{2}{c}{ Auditory Aspects } & N & $\%$ \\
\hline \multirow{2}{*}{ Cl time of use } & $\leq 2$ years and 11 months & 9 & 60 \\
& $\geq 3$ years & 6 & 40 \\
Implanted ear & RE & 12 & 80 \\
& LE & 3 & 20 \\
Speech Therapy & Yes & 11 & 73.33 \\
& No & 4 & 26.66 \\
Contralateral ISAD & Yes & 6 & 40 \\
& No & 9 & 60 \\
\hline
\end{tabular}

Legend: $\mathrm{N}=$ subjects number; $\mathrm{ISAD}=$ Individual Sound Amplification Device; $\mathrm{Cl}=$ Cochlear implant; $\mathrm{RE}=$ Right Ear; $\mathrm{LE}=$ Left Ear.

Table 2. Descriptive statistics of performance in the duration and frequency pattern test, according to the group $(n=30)$

\begin{tabular}{ccccccc}
\hline Tests & Minimum (\%) & Maximum (\%) & Mean (\%) & SD (\%) & Median (\%) & P-value \\
\hline DPT & & & & & & \\
Study Group & 33.33 & 100 & 77.33 & 19.52 & 80.00 & 0.95 \\
Control Group & 46.66 & 100 & 78.21 & 19.30 & 80.00 & \\
FPT* & & & & & & \\
Study Group & 16.66 & 93.33 & 40.21 & 23.07 & 33.33 & $0.00^{*}$ \\
Control Group & 36.66 & 100 & 65.10 & 23.19 & 56.66 & \\
\hline
\end{tabular}

Mann-Whitney Test

Legend: FPT = Frequency Pattern Test; DPT = Duration Pattern Test; $\mathrm{SD}=$ Standard Deviation; * $=$ significant $\mathrm{P}$-value $(\mathrm{p} \leq 0.05)$ 
There was a significant association in the performance of the FPT, that is, the individuals in the CG obtained better results for the test than those in the SG. For both groups, the performance obtained in DPT was better than in FPT.

The Kruskal-Wallis test was applied to verify the association between the performance of the DPT and
FPT in relation to the variable education; it was found that the subjects with higher education exhibited better results in the FPT $(p=0.06 *)$, in relation to the individuals with less education. Figure 1 shows the performance of the temporal tests according to the level of education.

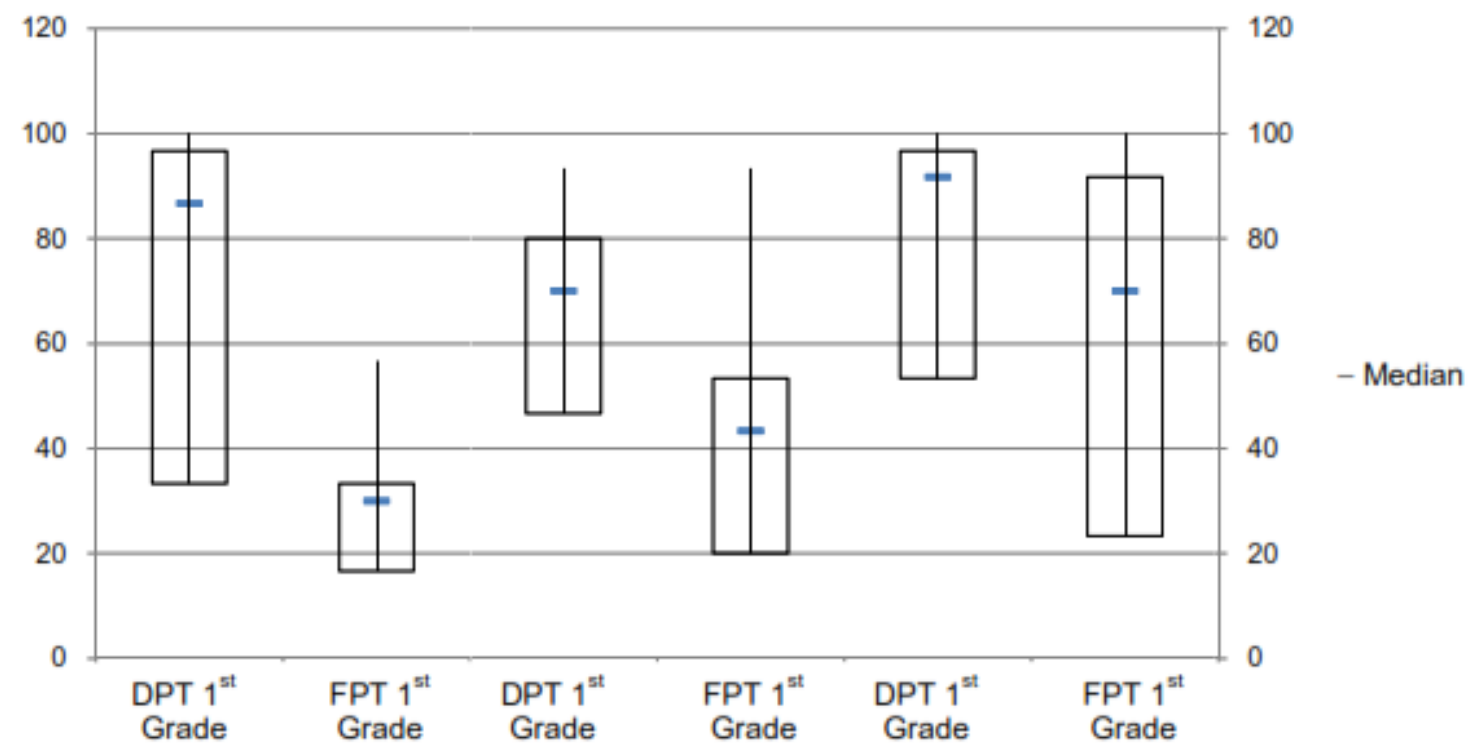

Legend: DPT= Duration Pattern Test; FPT = Frequency Pattern Test

Figure 1. Performance of individuals in the study group and control group, in relation to the educational level $(n=30)$

The performance of the SG in relation to gender, age, time of hearing deprivation, time of use of $\mathrm{Cl}$ and speech therapy can be seen in Table 3.

In addition, only an association of FPT with speech therapy was seen.
Regarding the performance of SG individuals according to the stimulation mode $(\mathrm{Cl}$ or $\mathrm{Cl}+$ contralateral ISAD), there was a significant association between users of bimodal stimulation and FPT (Table 4).

Table 3. P- Value of the association between the performance of patients using cochlear implants in temporal tests with audiological aspects $(n=15)$

\begin{tabular}{cccccc}
\hline Tests & Age & Gender & $\begin{array}{c}\text { Hearing deprivation } \\
\text { time }\end{array}$ & Cl usage time & Speech Therapy \\
\hline DPT & 0.57 & 0.15 & 0.17 & 0.23 & 0.16 \\
FPT & 0.25 & 0.67 & 0.19 & 0.51 & $0.01^{*}$ \\
\hline
\end{tabular}

Mann-Whitney Test

Legend: $\mathrm{Cl}=$ cochlear implant; FPT = Frequency Pattern Test; DPT = Duration Pattern Test; * $=\mathrm{P}$ value $(\mathrm{p} \leq 0.05)$ 
Table 4. Descriptive statistics and percentage of the individuals' performance in temporal ordering tests, according to the stimulation mode $(n=15)$

\begin{tabular}{cccccccc}
\hline Tests & N & Minimum (\%) & Maximum (\%) & Mean (\%) & SD (\%) & Median (\%) & P-value \\
\hline DPT & & & & & & & \\
Cl & 9 & 33.33 & 100 & 77.33 & 19.52 & 80.00 & 0.67 \\
CI +ISAD & 6 & 70 & 96.66 & 87.77 & 8.95 & 91.66 & \\
FPT & & & & & & & \\
Cl & 9 & 16.66 & 93.33 & 40.21 & 23.07 & 33.33 & $0.01^{*}$ \\
Cl +ISAD & 6 & 36.66 & 100 & 69.99 & 25.24 & 69.99 & \\
\hline
\end{tabular}

Mann-Whitney Test

Legend: ISAD = Individual Sound Amplification Device; $\mathrm{Cl}=$ Cochlear Implant; DPT = Duration Pattern Test; FPT= Frequency Pattern Test; SD = Standard Deviation;

* = significant $P$ value $(p<0.05)$

There was also a significant association between DPT and the implanted ear; individuals with $\mathrm{Cl}$ on the left side showed better performance in the test compared to those implanted on the right side (DPT $p=0.04 *)$, as can be seen in Figure 2. FPT showed no significant association between ears (FPT $p=0,82$ ).

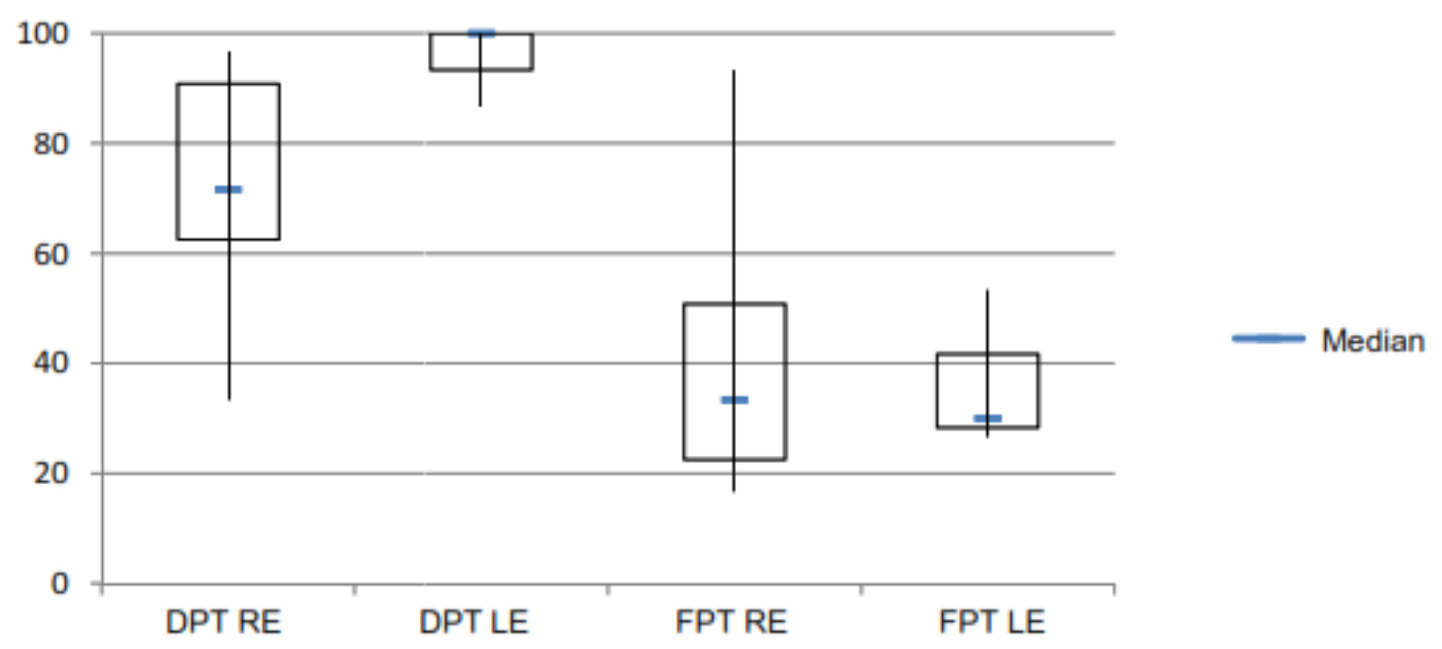

Legend: DPT = Duration Pattern Test; FPT = Frequency Pattern Test; RE = Right Ear; $L E=$ Left Ear

Figure 2. Percent performance of cochlear implant users in temporal tests, in relation to the implanted ear $(n=15)$

Figure 3 shows the types of errors made by the SG patients in the studied temporal tests.
For both temporal tests, $\mathrm{Cl}$ users showed a higher occurrence of discrimination errors. 


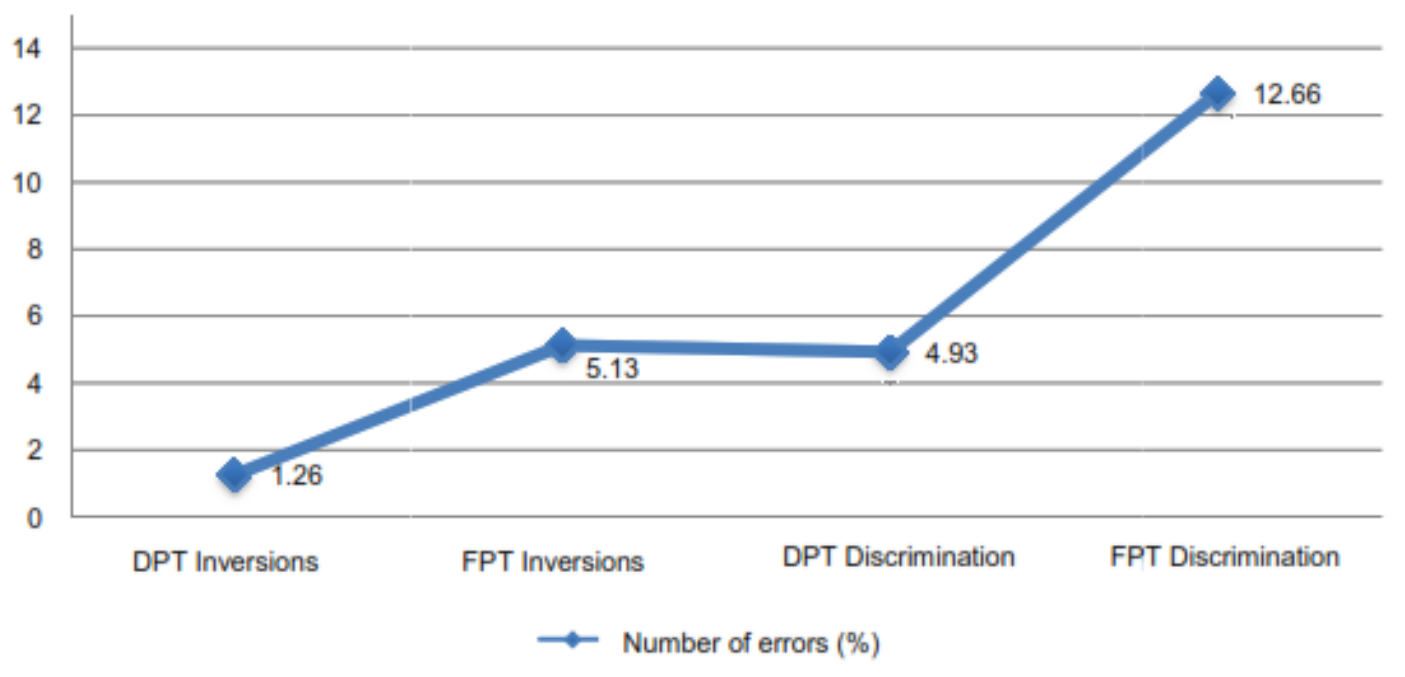

Legend: DPT = Duration Pattern Test; FPT = Frequency Pattern Test

Figure 3. Average percentage distribution of errors made by cochlear implant users, according to the test $(n=15)$

\section{DISCUSSION}

Studies on temporal processing in Brazil have grown significantly in recent years; however further expansion on the topic is still necessary in order to assist prevention, diagnosis, treatment and rehabilitation actions in various clinical populations ${ }^{24}$.

Monitoring the aspects related to the PAC in $\mathrm{Cl}$ users can help in the analysis of the performance of these subjects regarding the perception of speech and music, since the implanted device must be considered a component of the complex system that involves the auditory processing ${ }^{3,25}$.

The understanding about aspects such as the length of time of hearing deprivation, the form of communication, the type of rehabilitation used, the period of installation of the deafness, the etiology of the loss, significantly help the subject's auditory rehabilitation process $^{26}$.

Knowing the importance of the CAP for the processing of verbal and non-verbal speech stimuli, it should be noted that there are still few studies seeking to assess the auditory skills in the population using a $\mathrm{Cl}^{3,16}$.

In the present study, it is observed that $\mathrm{Cl}$ users had a lower performance in the FPT compared to the CG; these results indicate the presence of impairments in the hearing ability of temporal ordering in this population. However, there were no significant differences for the DPT.

Another study reviewed the hearing ability of temporal ordering in 14 users of a multichannel $\mathrm{Cl}$.
No significant differences were observed in the performance of the DPT and FPT of this population compared to normal-hearing individuals ${ }^{3}$. The data found in another study carried out with 12 subjects using unilateral $\mathrm{Cl}$ reinforces the findings of the present study, inasmuch as they verified a worse performance of this population in relation to normal hearing individuals for the $\mathrm{FPT}^{16}$.

A survey ${ }^{25}$ that assessed the performance of musical perception skills and temporal auditory skills before and after music therapy in post-lingual patients found that there was no difference in the performance of the frequency pattern test after the intervention. The authors found that the performance in the FPT was well below the normal range of normal hearing individuals and they believe that the time of sensory deprivation (31.9 years) may have influenced this performance.

The performance of $\mathrm{Cl}$ users seems to be more sensitive to FPT compared to DPT. It is believed that this result can be explained, among other factors, by the cochlear impairment present in the $\mathrm{Cl}$ users population, since the frequency distinction is present from the cochlea ${ }^{27}$.

When comparing the subjects who underwent speech therapy or not, there is a statistically significant association between the best performance in PTF and speech therapy $\left(p=0.01^{\star}\right)$, results not observed for DPT $(p=0,16)$.

Hearing rehabilitation, with the aid of electronic devices such as $\mathrm{Cl}$ and ISAD, aims to restore or develop the hearing perception capacity of individuals 
with hearing loss. In addition to audiological factors, motivation, family and patient expectations and the patient therapist relationship can influence the success of auditory rehabilitation. Rehabilitation should be guided by the training of auditory skills, so that the implanted patient can, in addition to perceiving, develop meaning for the auditory sensation received ${ }^{26}$.

In the current investigation it was found that the implanted side influenced DPT responses, with a better performance for $\mathrm{Cl}$ users on the left side (Figure 2). The information captured by the left ear is transferred to the right hemisphere, responsible for the processing of non-verbal stimuli, while the stimuli received through the right ear are directed to the left hemisphere, responsible for the processing of verbal information. This process occurs due to the crossing of most of the afferent fibers of the auditory pathway from the superior olivary complex $(\mathrm{SOC})^{27}$.

Analyzing the most prevalent type of error in the temporal tests, it appears that discrimination was the error with the highest occurrence (Figure 3 ). It is believed that due to hearing deprivation, individuals have difficulty discriminating, especially frequency. These results are in line with another study, in which there was a higher incidence of discrimination errors for $\mathrm{Cl}$ users evaluated with the FPT ${ }^{16}$. The difficulty of frequency discrimination found in the individuals of the present study enhances the need to train this hearing disability in this population.

The distinction in acoustic parameters present in DPT and FPT generates a greater or lesser degree of ease in performing the task, and the characteristics of the stimuli, such as frequency, duration and silence interval, influence the difficulty of the task ${ }^{10}$.

The presence of residual hearing is essential for the use of bimodal stimulation. Bimodal stimulation is a non-invasive way of providing binaural hearing, and has been suggested for patients who use unilateral $\mathrm{Cl}$ and who have residual hearing in the contralateral ear $^{28}$. One study ${ }^{29}$ found that approximately $60 \%$ of adult $\mathrm{Cl}$ candidates have residual hearing, mainly in low frequencies in at least one ear. Another more recent study ${ }^{30}$ found that in candidates to $\mathrm{Cl}$ surgery $72 \%$ had useful residual hearing.

The use of contralateral ISAD promotes important benefits to implanted individuals: bimodal stimulation can take advantage of residual hearing, improve the location of the sound source and assist in understanding the conversation, especially in environments with competitive noise'. However, a national study reports that bimodal stimulation is still little used by implanted patients, and this fact may be related to the lack of perception about the benefits brought by ISAD ${ }^{27}$.

In the literature, several studies were found with users of bimodal stimulation who were assessed speech recognition in noise $e^{6,29,31}$ and only a few studies with bimodal stimulation relating the temporal aspects ${ }^{16}$.

In this study, it was found that $\mathrm{Cl}$ users who took advantage of bimodal stimulation performed better for FPT compared to users of $\mathrm{Cl}$ only. In the clinical practice this finding in users of bimodal stimulation may contribute, in raising awareness on the importance of use of contralateral ISAD in individuals with residual hearing. Since the temporal aspects are important for the auditory skills of understanding speech, reading and music, the use of bimodal stimulation can bring better benefits to patients in their daily life and leisure activities.

The assessment of central auditory skills in monitoring $\mathrm{Cl}$ users can contribute to obtain new information, knowledge and technologies, generating greater benefits for this population. It is suggested that the reference services in cochlear implant include at least one temporal test in their clinical routine, such as the frequency pattern, in order to reap one more parameter that helps in the monitoring of cochlear implant users.

\section{CONCLUSION}

Through this investigation, it was possible to conclude that the users of unilateral $\mathrm{Cl}$ presented changes in the performance of their auditory ability of temporal ordering. The use of bimodal stimulation, speech therapy and education influenced the performance of PTF, while the implanted side influenced the performance of DPT.

\section{REFERENCES}

1. Diges I, Simón F, Cobo P. Assessing auditory processing deficits in tinnitus and hearing impaired patients with the Auditory Behavior Questionnaire. Front Neurosci. 2017;11:187.

2. Correia R, Pinheiro C, Paiva F, Gomes Neto P, Rodrigues $T$, Mendonça $A$ et al. Reabilitação auditiva por aparelhos de amplificação sonora individual (AASI): perfil epidemiológico de pacientes adaptados em um hospital terciário em 5 anos. RevMed UFC. 2017;57(2):26-30. 
3. Campos P, Alvarenga K, Frederigue N, Nascimento L, Sameshima K, Costa Filho O et al. Habilidades de ordenação temporal em usuários de implante coclear multicanal. Braz J Otorhinolaryngol. 2008;74(6):884-9.

4. Vieira SS, Dupas G, Chiari BM. Effects of cochlear implantation on adulthood. CoDAS. 2018;30(6):e20180001.

5. Generoso GF, Magalhães ATM, Goffi-Gomez MVS, Tsuji RK, Bento RF. Self-reported perception of unilateral cochlear implantees on the contralateral use of hearing aid. Distúrb. Comunic. 2019;31(3):369-79.

6. Vroegop JL, Goedegebure A, Schroeff MPV. How to optimally fit a hearing aid for bimodal cochlear implant users: a systematic review. Ear \& hearing. 2018;39(6):1039-45.

7. Matos G, Frota S. The influence of sensoryneural hearing loss on temporal ordering. Rev. CEFAC. 2013;15(6):1435-40.

8. Cavalcante MV, Bittencourt IGS, Vieira ACS, Carneiro JN, Teixeira LM. The scenario of researches regarding life experiences with cochlear implants: an integrative literature review. Rev. CEFAC. 2020;22(1):e15818.

9. Catts HW, Chermak GD, Craig $\mathrm{CH}$, Johnston JR, Keith RW, Musiek FE et al. Central auditory processing:current status of research and implications for clinical practice. Am J Audiol. 1996;5(2):41-52.

10. Pereira LD, Frota $S$. Avaliação do processamento auditivo - testes comportamentais. In: Boéchat EM, Menezes PL, Couto CM, Frizzo ACF, Scharlarch RC, Anastacio ART (orgs).Tratado de Audiologia. $2^{2}$ ed.Rio de Janeiro: Guanabara Koogan; 2015.p. 160-70.

11. Shinn J. Temporal processing: the basics. Hear J. 2003;56(7):52.

12. Schochat E, Andrade A, Takeyama F, Oliveira J, Sanches S. Processamento auditivo: comparação entre potenciais evocados auditivos de média latência e testes de padrões temporais. Rev. CEFAC. 2009;11(2):314-22.

13. Terto S, Lemos S. Aspectos temporais auditivos: produção de conhecimento em quatro periódicos nacionais. Rev. CEFAC. 2011;13(5):926-36.

14. Holden LK, Finley CC, Firszt JB, Holden TA, Brenner C, Potts $L G$ et al. Factors affecting open-set word recognition in adults with cochlear implants. Ear Hear. 2013;34(3):342-60.
15. Pisoni DB, Kronenberger WG, Harris MS, Moberly AC. Three challenges for future research on cochlear implants. World J Otorhinolaryngol Head Neck Surg. 2018;3(4):240-54.

16. Duarte M, Gresele A, Pinheiro M. Temporal processing in postlingual adult users of cochlear implant. Int Arch Otorhinolaryngol.2016;82(3):304-9.

17. Valente SLO. Elaboração de listas de sentenças construídas na língua portuguesa [dissertação]. São Paulo (SP):Pontifícia Universidade Católica; 1998.

18. OMS: Organização Mundial de Saúde-2014. http:// www.who.int/pbd/deafness/hearing_ impairment grades/en/ acesso em 20.09.2017.

19. Summers SA. Factor structure, correlations, and mean data on Form A of the Beta III version of Multiple Auditory Processing Assessment. Pocatello, ID: Idaho State University; 2003.

20. Trammell J. A new approach to speech audiometry. J Speech Hear Disord. 1968;33(4):318.

21. Jerger J, Jerger S, Mauldin L. Studies in impedance audiometry. Normal and sensorineural ears. Int Arch Otorhinolaryngol. 1972;96(6):513-23.

22. Musiek FE, Baran JA, Pinheiro ML. Duration pattern recognition in normal subjects and patients with cerebral and cochlear lesions. Am J Audiol. 1990;29(6):304-13.

23. Musiek FE. Frequency (pitch) and duration pattern tests. J Am Acad Audiol. 1994;5(4):265-8.

24. Delecrode C, Cardoso A, Frizzo A, Guida H. Pitch pattern sequence and duration pattern tests in Brazil: literature review. Rev. CEFAC. 2014;16(1):283-93.

25. Lima JP, lervolino SMS, Schochat E. Musical and temporal auditory skills in cochlear implant users after music therapy. CoDAS. 2018;30(6):e20180006.

26. Scaranello CA. Reabilitação auditiva pós implante coclear. Medicina. 2005;38(3/4):273-8.

27. Yawn RJ, O'Connell BP, Dwyer RT, Sunderhaus LW, Reynolds S, Haynes DS et al. Bilateral cochlear implantation versus bimodal hearing in patients with functional residual hearing: a whitin-subjects comparison of audiologic performance and quality of life. Otol Neurotol. 2018;39(4):422-7.

28. Amaral MSA, Damico TA, Gonçales AS, Reis ACMB, Isaac ML, Massuda ET et al. Is there a best side for cochlear implants in post-lingual patients? Braz J Otorhinolaryngol. 2018;84(5):560-65.

29. Dorman MF, Cook S, Spahr A, Zhang T, Loiselle L, Schramm $D$ et al. Factors constraining the benefit 
to speech understanding of combining information from low-frequency hearing and a cochlear implant. Hear Res. 2015;322:107-11.

30. Holder JT, Reynolds SM, Sunderhaus LW, Gifford $\mathrm{RH}$. Current profile of adults presenting for preoperative cochlear implant evaluation. Trends Hear. 2018;22(2331216518755288):1-16.

31. Blamey PJ, Maat B, Başkent D, Mawman D, Burke $\mathrm{E}$, Dillier $\mathrm{N}$ et al. A retrospective multicenter study comparing speech perception outcomes for bilateral implantation and bimodal rehabilitation. Ear Hear. 2015;36(4):408-16. 